\title{
Changes in the Global Economic Environment
}

\subsection{Introduction}

Understanding economic changes at the global level is critical to the formulation of global business strategies. In Chap. 1, we provided an overview of the economies of newly developing countries, particularly China and India, although many other regions throughout the world-including Southeast Asia, Latin America, and Africa-are expected to become major markets. Advanced countries and regions, such as the U.S. and Europe, are currently the most promising overseas markets for Japanese companies, but how will the rankings of these advanced markets change in the future? In this section, we consider the changes in the global economic environment by focusing on the changes in the GDP of countries around the world.

In addition to examining the long-term GDP growth rate of various countries, we first discuss the determinants of economic growth that vary by country. Companies entering overseas markets must be prepared to make long-term investments spanning 10 or 20 years. Therefore, it is critical to understand each country's long-term economic trends. In this section, we discuss philosophies of long-term economic growth based on economic growth theory.

Next, in Sect. 3.3, we introduce an economic forecast for various countries and regions for 2030. In addition to the GDP scale, we present forecasts for per capita GDP and describe how the advanced countries of Japan, the U.S., and Europe, as well as the developing nations, will change. Per capita GDP not only gives us the average income levels (i.e., purchasing power) but also is an indicator of labor costs. It is a fundamental concept used when expanding overseas and, as noted in Chap. 2, is the most important metric for determining whether a country should be viewed "as a market or as a factory."

Finally, we explain the concept of international competitiveness and its most common indicator, the IMD's World Competitiveness Index. International competitiveness can be thought of as synonymous with a country's long-term economic growth potential. The IMD created this index using qualitative data, such as the 
quality of corporate management and governments, based on a questionnaire survey of managers from around the world. This is very valuable data for considering global strategies, as it provides diverse information on approximately 60 countries around the world.

\subsection{Long-Term Economic Growth by Country}

The world has many countries, and each country has a different pattern of economic level. Tremendous disparities exist among nations in terms of per capita GDP. In Japan and other advanced nations, per capita GDP is at a level of several tens of thousands of dollars, whereas some countries have per capita GDPs of only several hundred dollars. Figures 3.1 and 3.2 show post-World War II changes to per capita GDP by country and region (with purchasing power in 1990 U.S. dollars). We created two categories of per capita GDP as of 2008: developed nations with per capita GDP above \$20,000 (the U.S., Singapore, Hong Kong, Japan, Western Europe, and Taiwan), and developing countries with per capita GDP below \$10,000 (countries of

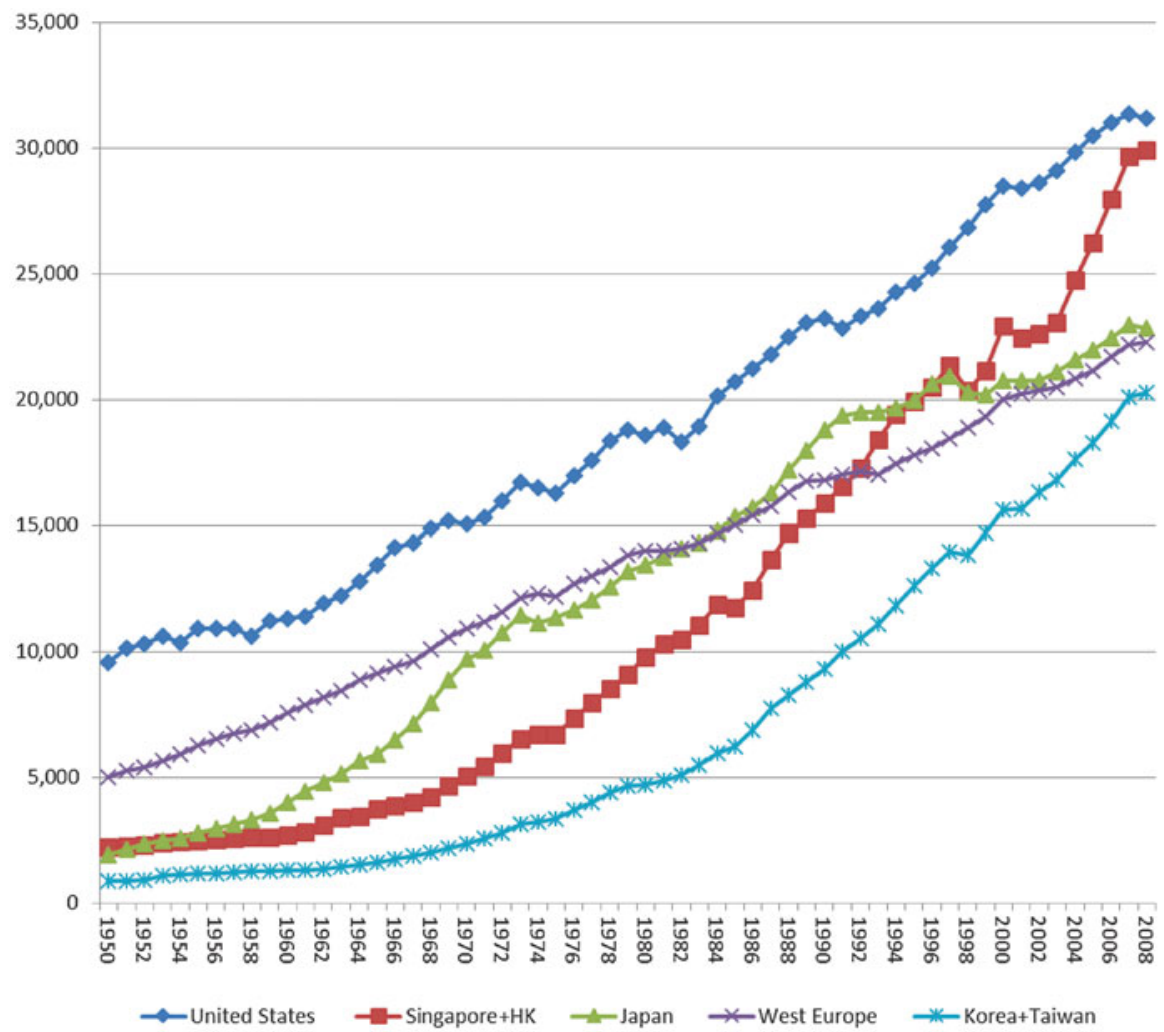

Fig. 3.1 Per capita GDP in U.S. dollars (developed countries) 


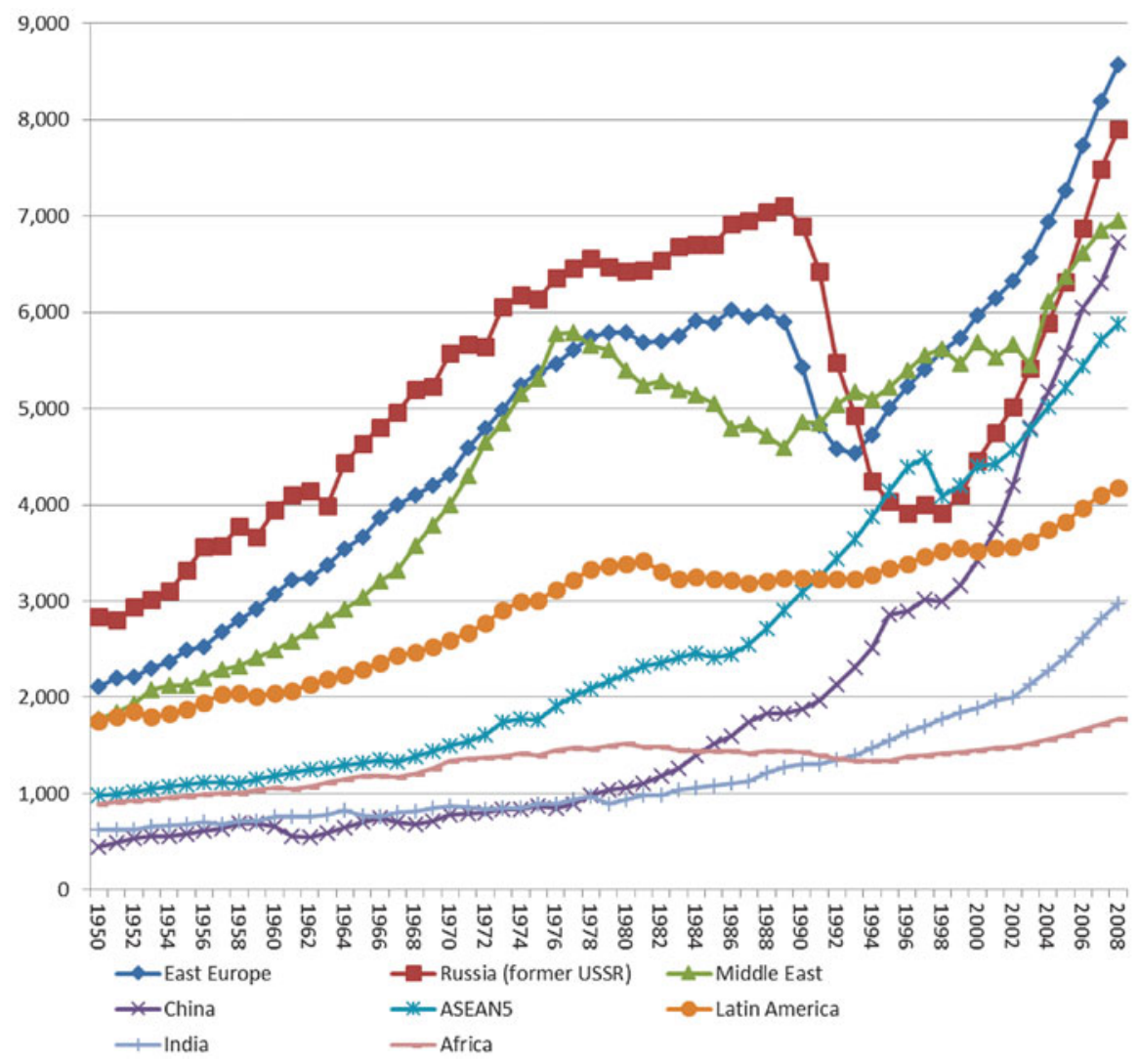

Fig. 3.2 Per capita GDP in U.S. dollars (developing countries) (Source: Angus Maddison's longterm GDP growth statistics)

the former Soviet Union, Eastern Europe, ASEAN countries, Latin American countries, India, and African countries).

Japan caught up with the advanced nations of Western Europe and the U.S. during the post-war era. Japan's per capita GDP surpassed Western Europe's in the mid-1980s, but its growth stalled in the 1990s and it has fallen farther behind the U.S. in the recent years. Meanwhile, per capita GDP in the city-states of Singapore and Hong Kong is rapidly approaching that of the U.S. South Korea, Taiwan, and other new industrial economies (NIEs) experienced growth after the 1980s and have recently been approaching the level of Japan and Western Europe. When we examine the trends in the developing nations (Fig. 3.2), China's recent growth is particularly striking. In the past, the countries of the former Soviet Union (Russia and surrounding nations) and Eastern Europe had stronger economies than Japan; however, the collapse of the Soviet Union in 1991 and subsequent economic chaos brought stagnation and reduced these countries to a level averaging that of the developing nations. However, economic growth in Russia and Eastern Europe has 
recently surged, and these countries, along with China, appear to be catching up to the developed nations. The Southeast Asian countries of Indonesia, Malaysia, the Philippines, Thailand, and Vietnam have achieved startling economic growth since the 1980s. Although China surpassed them in the 2000s, they are still growing more rapidly than the developed nations. That being said, the countries of Latin America, India, and the countries of Africa face stagnated economic growth, and these economies have remained at a low level of development. Africa, in particular, has been completely left behind in terms of global economic development. India's growth rate picked up in the 2000s, and seems to have taken a step up from its former poverty levels, which are still seen in Africa.

Economic growth theory is a field that researches these types of global economic growth patterns. Economic growth requires growth in the population (i.e., labor force), as well as the accumulation of capital and improvements to technology. Classical economic growth models, such as that of MIT's Robert Solow, explain economic growth as occurring through exogenous technological innovations, population growth, and capital accumulation. As economic development progresses, companies automate their production processes and improvements are made to such infrastructure networks as roads, railways, electric power, and water and sewage systems across the entire nation, thereby increasing the capital stock per capita. Accordingly, economic growth exceeds the rate of population growth. The increased per capita economic growth witnessed to date is due to the worldwide occurrence of this phenomenon.

As capital accumulates, the marginal productivity of capital decreases and the economic growth rate slows. Accordingly, there tends to be a negative relationship between per capita GDP and economic growth rate, and this trend has been confirmed in many studies. The classical model of Solow states that the speed of capital accumulation will ultimately falls below the population growth rate, and economic growth will decelerate to the speed of technological innovation, which is exogenously impacted by the population growth rate. In this basic model, economic growth is determined by levies imposed on the factors of production held by each country, and is not influenced by government policies for deregulation or to create innovation that are so often observed in growth policy roadmaps.

However, recent research focused on economic externalities caused by technology spillover effects, and a new theory has arisen that emphasizes on the importance of innovation on economic growth. This theory of endogenous economic growth focuses on technological innovation, which was treated as exogenous in the Solow model, and treats R\&D activities as endogenous. A part of GDP is given over to capital accumulation as equipment investment; likewise, the portion given to R\&D spending is allocated to knowledge accumulation. This knowledge (technology stock) is fundamental to such innovations as new products and production process improvements (Grossman and Helpman 1993). Unlike capital stock, knowledge and technology are intangible assets and thus can be shared with others. Through this characteristic of non-rivalry, investment in knowledge stock benefits not only the investors, but the whole of society. Accordingly, policies to promote R\&D through 
subsidies and tax measures can spur the rapid accumulation of knowledge stock and ultimately increase the rate of economic growth. This theory of endogenous economic growth allows for the use of investments in infrastructure as well as in education and other human capital, similar to investments with economic externalities. It is a useful model for evaluating growth strategies.

Robert Barrow and Xavier Sala-i-Martin used economic growth data from 87 countries to conduct a quantitative analysis of long-term economic growth determinants (Barro and Sala-i-Martin 2003). Taking 10-year average economic growth rates (divided into three 10-year periods from 1965 to 1995) as a non-explanatory variable, they ran a multiple regression analysis using per capita GDP for the initial year in each 10-year period, as well as the following variables.

- Variables related to human capital, such as the percentage of male adults who received higher education, infant mortality rates, and birthrates.

- Variables related to the macroeconomic environment, such as ratio of capital investment to GDP, the rate of inflation, and trade indices.

- Variables related to socioeconomic systems, such as the degree of democratization, the effectiveness of courts, and government expenditures as a percentage of GDP.

As can be seen from this theoretical model of economic growth, there is a significant correlation between these explanatory variables and the economic growth rate. We conducted an analysis of whether, in addition to the above variables, regional characteristics lead to differences in economic growth. The results of this analysis clearly show that Japan, China, South Korea, and other countries in East Asia enjoy a higher economic growth rate than elsewhere. Research, including a research project by the World Bank, has been conducted on Asian economic development that demonstrates the influence of investment in human resources and a stable macroeconomic environment (World Bank 1993). However, these variables are already part of the estimation model and, moreover, show that East Asia has high economic growth. In other words, the results suggest a regional characteristic that can, perhaps, be termed an Asia Model that goes beyond economic growth models. Research by MIT's Daron Acemoglu and others shows that economic growth during the colonial era varied according to the colonial power (Acemoglu et al. 2001). Compared with British colonies, colonies controlled by Spain were slow in forming property rights systems governed by the rule of law, and this slowed the development of market economies. The results of this study showed that, in addition to controlling economic variables, those colonies had lower economic growth rates. Thus, when considering international competitiveness (or long-term economic growth), such institutional factors as the historical background and overall socioeconomic circumstances of each country should also be considered, in addition to economic variables that are explained by economic growth theories. We discuss this in greater detail in Chap. 3 by way of a comparison of China and India. 


\subsection{The Global Economic Forecast for $\mathbf{2 0 3 0}$}

In October 2003, Goldman Sachs published a report entitled "Dreaming with BRICs: The Path to 2050." This report predicted that China's GDP would surpass Japan's by 2015, and that, by 2040, it would overtake that of the U.S., becoming the largest in the world; India's economy was predicted to be the same size as Japan's around 2030. The report highlighted the BRICs' economies. In the 10 years since the report was published, China's economic growth has accelerated; its GDP exceeded that of Japan in 2009.

We built a long-term economic growth model for 80 countries to understand how the economic balance between developed and developing nations in the global economy would change. The model did not examine most African nations (only South Africa, Egypt, Algeria, and other larger countries were included) or small island nations; however, it did cover more than $90 \%$ of the world's overall GDP as of 2010 (Motohashi 2014).

Figure 3.3 shows the 2030 forecast of GDP shares (in US dollars) by country and region, based on this model. The share held by the developed nations (Japan, North American countries, and Western European countries) was about $85 \%$ until 1990. This percentage began to shrink in 2000 and is expected to drop to almost $40 \%$ by 2030. Japan's share of the global economy was $15 \%$ until 2000 , but will contract to less than $5 \%$ in 2030. Japan's position in the global economy will become marginal. On the other hand, China's share will grow to approximately $18 \%$ by 2030 , and India's will increase to about $6 \%$. The shares of Brazil and other Latin American countries, Russia and other Eastern European/Eurasian countries, and Middle

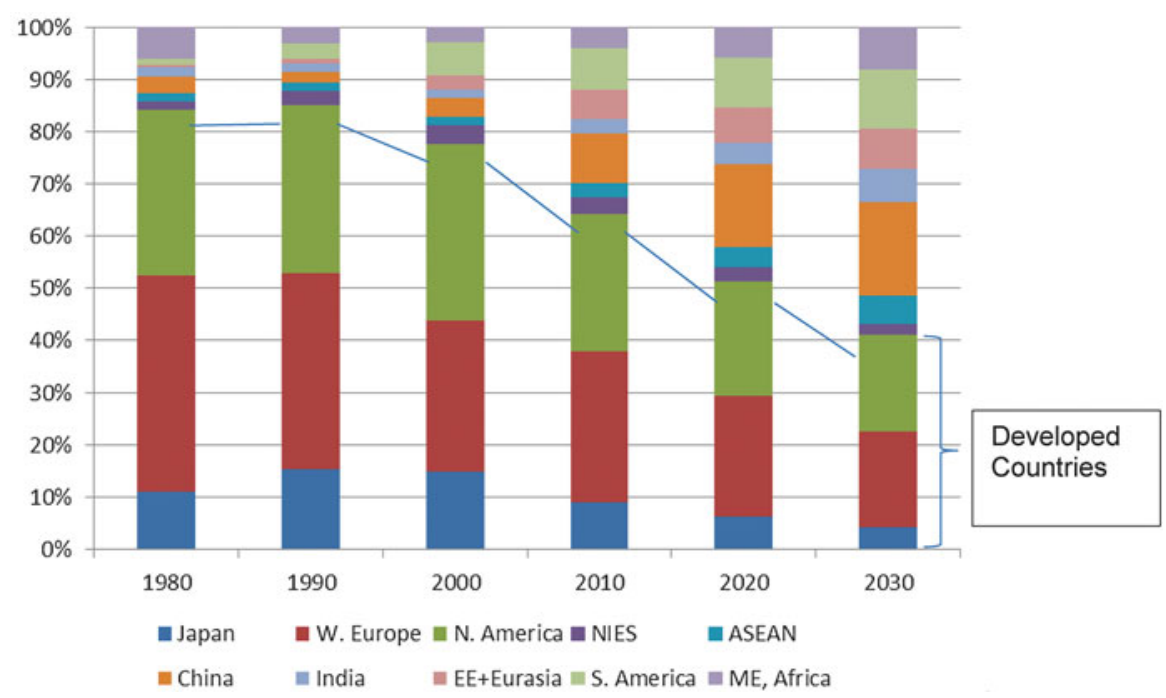

Fig. 3.3 Changes in shares of GDP (in nominal U.S. dollars) 
Eastern and African countries will grow. These estimates also show that by 2030 , China's GDP will be as large as that of the U.S., and India's GDP will surpass Japan's.

These estimates were generated by reverse-engineering of calculations for growth factors, i.e., by forecasting investments in labor and capital, and then adding total factor productivity (TFP) to calculate potential economic growth. When forecasting long-term economic growth, it is important to factor in changes in the composition of the population. As a simple explanation of our model structure, we first determine investment in labor by forecasting the future working-age population (those between 20 and 65 years of age) using UN population estimates. For capital stock, we subtract depreciation from the starting point (2010) for future projections, and then add new equipment investment to determine next-period capital stock (the perpetual inventory method). Repeating these steps enables us to determine the path of capital accumulation. Equipment investment is determined by the savings rate (the I-S balance), and the savings rate is affected by the ratio of elderly people in the population (or the ratio of elderly to working-age individuals). This is because an aging society increases consumption in society overall, and lowers the savings rate. Furthermore, total factor productivity (TFP) is set to an annual rate of $1 \%$ for all countries. While it may be possible to use past trends in the TFP of each country, we set our baseline at a certain value due to issues with the accuracy of our statistical data, and then adjusted this value by country and period as necessary. Even if we were to set the post-2010 TFP growth rate to $2 \%$ rather than $1 \%$ for Japan alone, the share of Japan's GDP would only rise by $1.2 \%$, i.e., from 4.3 to $5.5 \%$. Furthermore, it is rare for a country to have an average long-term TFP growth rate of more than $2 \%$, and it is hard to imagine that political instability, i.e., wars, or other large external shocks causing negative TFP would not occur. Accordingly, any assumptions we made on TFP are not likely to have much of a negative impact on the accuracy of the results of our forecast.

In "The World Is Flat," Thomas Friedman discussed the notion that the world is becoming "flatter," with less awareness of national borders due to internet-based innovations and negotiated trade via the WTO or FTAs (free trade agreements) and EPAs (economic partnership agreements). To be sure, when one visits the campus of Infosys in Bangalore, India, the subject of the beginning of the book, one does get a sense of this "flattening." The campus is located in a beautiful park-like complex, replete with modern buildings. The company's many engineers provide IT services primarily to Western companies. The department that offers maintenance services for remote computers, work the same hours as their clients. Thus, people in India work in the time zones of eastern U.S. as well as the European continent. The power of the internet allows people to experience such a flattened world.

However, when Infosys employees step off their corporate campus, they are greeted with the roadside stalls and motorized rickshaws that are common in India. Sales per capita at Infosys is less than one-tenth that of IBM. Compared with the U.S., wages in India are very low. Of course, the rise of Infosys and other Indian IT companies puts downward pressure on U.S. software engineers' compensation. 


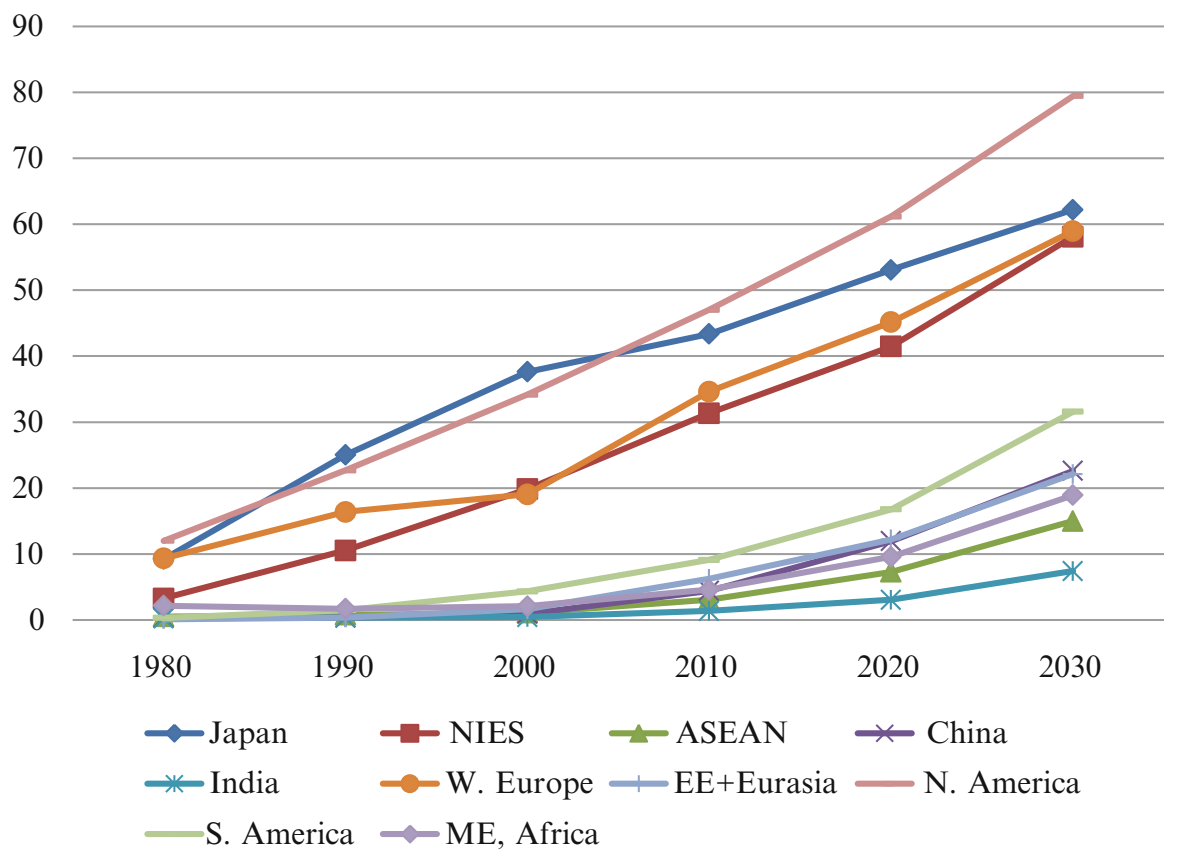

Fig. 3.4 Changes in per capita GDP

However, because of restrictions on trans-border migration the labor markets of India and U.S. will never be consolidated. The world is, perhaps, becoming flatter, but it is a long way from being flat.

The GDPs of China, India, and other developing nations are growing, and the developed nation-centric global economic structure appears to be changing. At the same time, income levels in developing nations are rising. Will they catch up to the developed nations? If they do, then the world will truly be flat. In Fig. 3.4, we note that, at least through 2030, the developed-versus-developing picture will remain unchanged. In this section, we focus on changes to per capita GDP and identify two distinct groups: the developed nations of North America, Western Europe, Japan, and the NIEs (South Korea, Taiwan, Singapore, and Hong Kong); and the developing nations of China, India, Latin America, Eastern Europe/Eurasia, the Middle East, and Africa. By 2030, the per capita GDP of Latin America will be approximately $\$ 30,000$, and that of China will rise to about $\$ 20,000$. These are in nominal terms. When we consider inflation, these levels will still not equal those of the developed nations.

While such differences between developed and developing nations will prevail, developing nations will have a greater economic presence. From the perspective of Japanese corporations, the global strategy till date has entailed expansion in western nations with economic environments similar to Japan's. Having achieved that goal, companies then expanded into lower-ranked developing economies, 
although on a smaller scale. In the future, however, companies must aim their strategic focus on developing countries, particularly newly developed countries experiencing high growth.

A brief comment on the trend in Japan's per capita GDP: until 2010, Japan's per capita GDP was as high as that of the U.S., but by 2030 this gap is expected to increase, and Japan's per capita GDP will be in a par with those of Western Europe and the NIEs. Japan's relative decline among the developed nations is due to its aging population. The working-age population will decline as a percentage of the overall population, and this will bring down the per capita productivity. In addition, the aging society will lead to a decline in the savings rate, along with a deceleration in the rate of capital accumulation as equipment investment contracts. Japan's elderly (those 65 and older) in 2010 comprised just under $40 \%$ of the population. This will increase to more than $50 \%$ by 2020 , and almost $60 \%$ by 2030 . Population aging is seen in all developed nations, although the ratio of the elderly in the populations of Europe, North America, and the NIEs will all average around $40 \%$. Thus, the aging rate in Japan is extraordinarily high even among developed nations and, accordingly, GDP growth will be slower in Japan than in other countries.

\subsection{Competitiveness Rankings: IMD's World Competitiveness Yearbook}

Countries' economic growth rates are influenced by many factors, such as innovation and type of economic infrastructure, as well as capital stock, population, and other elements of production. Where should a company develop its business globally? Companies must carefully survey both the current circumstances and future outlook of the economic environment of candidate countries. When doing so, a valuable resource is the World Competitiveness Yearbook, published by IMD, an international management development center and business school located in Lausanne, Switzerland.

IMD gathers as many indices related to international competitiveness as possible for compilation in the World Competitiveness Yearbook, which it has published since 1989. The Global Competitiveness Index, published by the World Economic Forum (WEF) of Davos fame, is a similar index. This group worked with IMD until 1995, after which it published its own index.

These reports gather enormous amounts of data from countries worldwide related to national economic competitiveness, and then rank countries using weighted averages of these data. Incidentally, Japan's recent rankings are 24th of 60 in the IMD index (2013), and 10th of 144 in the WEF index (2012). These rankings greatly differ in their method of calculation and the factors used, although the IMD's rankings get the most attention. The IMD index is older, and the 248 factors that form the basis of the overall rankings and far outnumber those used by the WEF (111). The IMD index ranked Japan as number one for 4 years in a row from 1989, the year of the index's inception, to 1993. However, in the latter half of the 1990s, Japan quickly fell in the rankings, and continues to struggle. We shall offer an explanation of the IMD indices before considering the appropriateness of its assessment. 
The IMD's competitiveness rankings consolidate various types of statistical data, such as GDP, technology research and investment, workers' compensation levels, and financial market size, in addition to qualitative assessments based on questionnaire responses provided by 4,200 corporate managers throughout the world. In addition to an overall ranking, countries are also ranked in various hierarchical categories (Table 3.1). Major categories consist of four factors: economic performance, government efficiency, business efficiency, and infrastructure. These major factors are further broken down into subfactors. As can be seen from the content of the major factors, IMD's philosophy of international competitiveness is to examine the efficiency of both public and private sectors in achieving economic performance, which is an output index. Moreover, the conditions of both hard and soft infrastructure that support economic activity on a nationwide basis are included. Thus, there is a mixture of both input and output indices, with the overall index being calculated as a weighted average of the various scores assigned to the abovementioned data.

The IMD's philosophy of international competitiveness was influenced by Michael Porter's Competitive Advantage of Nations. In this book, Porter explains the diamond model that consists of four components of production: human resources and technology, corporate strategy, demand conditions for product markets, and related industries (Porter 1990). In addition, Porter correlates these components and emphasizes on the importance of understanding them in the context of an overall system. Among the subfactors relating to business efficiency, the IMD's competitiveness index primarily uses items related to Porter's framework, such as indices related to productivity, indices related to such production resources as labor markets and capital markets, and indices critical to business strategy, such as customer satisfaction. Moreover, technology, which is of increasing importance in terms of productivity, are dealt with as infrastructure.

In addition to economic indices directly related to the abovementioned corporate activities, the IMD's index is distinctive for also considering efficiency in the public arena and social policies related to the people's quality of life. For example, in the field of economics, it has been shown that the level of political risk and transparency in government policymaking are related to a country's growth. Moreover, securing public healthcare services and the safety of citizens has the effect of increasing a country's attractiveness, thereby stimulating the entry of overseas businesses. However, these factors have an indirect impact on economic performance. While, perhaps, appropriate for comparing developed countries with developing countries, where large gaps exist in the level of social infrastructure, it is difficult to compare two developed nations that are at almost the same level. Furthermore, as with "adaptability in response to change" and "propensity toward social uniformity," in a sense, some of these variables enter into the realm of national identity and values, and their relationship with international competitiveness is unclear.

Another issue with the IMD rankings is that they are based on questionnaires given to corporate managers. In the overall index, the ratio of hard data based on statistics to opinion data is said be about 2:1. In assessing the various subfactors for each country, it is possible that some global managers may not very well understand Japan's situation. In that case, global public opinion may influence the assessments. The stagnation of the Japanese economy since 1990 is a well-known fact, but the 


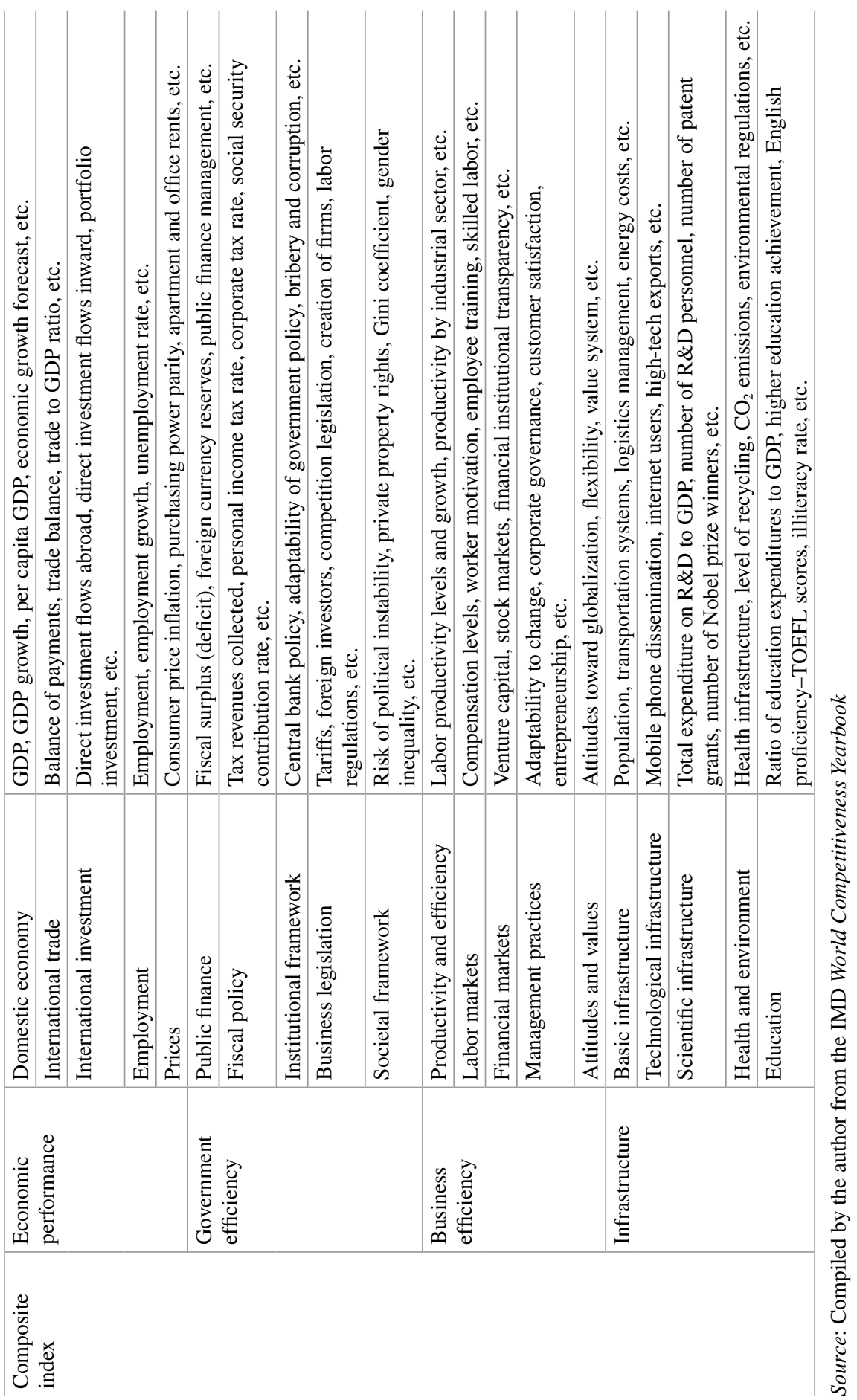


global opinion on Japanese economy is becoming harsher. These indices already incorporate factors related to economic performance, but it is possible that a downward bias exists due to opinion surveys that are increasingly critical of the Japanese government and Japanese corporations.

However, when it comes to the breadth of factors related to international competitiveness, the IMD world competitiveness index is significant in that it gathers comprehensive data that enables international comparisons. These include many important factors used in various discussions on international competitiveness. Recently, the IMD began offering downloads of prior years' data via the Internet, a valuable service that opens up their database on competitiveness. Data aggregation methods influence the rankings in the composite index, but the data is very useful for examining the rankings by factor in detail.

Japan's overall ranking in the 2013 IMD world competitiveness index is 24th of 60 countries. Is this an appropriate ranking? Let us assess the validity of this ranking by comparing Japan, the U.S. (composite ranking of 1), and China (21). Table 3.2

Table 3.2 Rankings of Japan, the U.S., and China (2013)

\begin{tabular}{|c|c|c|c|}
\hline & Japan & U.S. & China \\
\hline Composite ranking & 24 & 1 & 21 \\
\hline \multicolumn{4}{|l|}{ Economic performance } \\
\hline Domestic economy & 5 & 1 & 3 \\
\hline International trade & 56 & 9 & 20 \\
\hline International investment & 16 & 1 & 8 \\
\hline Employment & 12 & 22 & 1 \\
\hline Prices & 53 & 6 & 42 \\
\hline \multicolumn{4}{|l|}{ Government efficiency } \\
\hline Public finance & 60 & 55 & 14 \\
\hline Fiscal policy & 37 & 26 & 55 \\
\hline Institutional framework & 17 & 11 & 13 \\
\hline \multicolumn{4}{|l|}{ Business efficiency } \\
\hline Business legislation & 29 & 12 & 55 \\
\hline Societal framework & 24 & 22 & 44 \\
\hline Productivity and efficiency & 28 & 5 & 31 \\
\hline Labor markets & 39 & 18 & 3 \\
\hline Financial markets & 13 & 1 & 32 \\
\hline Management practices & 18 & 13 & 40 \\
\hline Attitudes and values & 35 & 15 & 30 \\
\hline \multicolumn{4}{|l|}{ Infrastructure } \\
\hline Basic infrastructure & 27 & 6 & 8 \\
\hline Technological infrastructure & 21 & 2 & 20 \\
\hline Scientific infrastructure & 2 & 1 & 8 \\
\hline Health and environment & 8 & 19 & 54 \\
\hline Education & 28 & 18 & 45 \\
\hline
\end{tabular}

Source: Compiled by the author from the IMD World Competitiveness Yearbook 
shows the rankings of these three countries by factor. Rankings where Japan appears in the top 10 are "domestic economy," "scientific infrastructure," and "health and environment." On the other hand, in some areas, Japan ranks below 50 (i.e., in the bottom 10), namely, "international trade," "prices," and "public finance."

The score for "domestic economy" is heavily weighted toward the size of a country's GDP or economy. Accordingly, countries with large economies are at an advantage. Japan, the U.S., and China are the top three countries in terms of GDP, and the U.S. and China are therefore ranked 1st and 3rd, respectively. The size of a country's economy illustrates the size of its domestic market, so a larger economy is a good thing for that country's companies. "Scientific infrastructure" is the ratio of R\&D spending to GDP, as well as the number of scientific papers and patents generated by a country. When considering a country's competitiveness, this can be thought of as an indicator of a country's level of innovation. Along with Japan, the U.S. and China both rank highly in this area. "Health and environment" is a mixture of indices, such as average life expectancy, level of public health, carbon dioxide emissions, renewable energy, and energy efficiency. While these have no direct relationship to economic growth, they do indicate improvements in the quality of life, something that cannot be measured by economic indicators. In regard to this factor, China significantly falls in the rankings.

Japan's ranking in "international trade" is low. This index is calculated using the balance of trade and ratio of imports and exports to GDP. In contrast to the domestic economy index, countries with large economies are less reliant on trade, so large countries tend to fall in the rankings. However, when direct investment leads to the establishment of overseas bases, an alternative effect on trade emerges; thus, this factor must be viewed in conjunction with the next one, "international investment." In this area, Japan ranks 16th, because while Japan's level of direct investment abroad is high, the level of internal direct investment brings the country down in the rankings. At the same time, the U.S. makes strong international investments both internally and externally, and is ranked 1 st in this area. Despite the absence of inflation, Japan's low ranking in "prices" is due to its persistently high price levels from a global perspective. Finally, in regard to "public finance," Japan continues to run a fiscal deficit, much like the U.S. In contrast, China has no glaring issues regarding its finances. Even apart from this, the Japanese government is given low marks overall in areas such as "fiscal policy" and "institutional framework."

As we examine factors related to business efficiency, we see that the U.S. is ahead, followed by Japan, and then China. Japan, in particular, trails the U.S. in such areas as "business legislation," "productivity and efficiency," and "financial markets." For its part, China lags Japan in "business legislation," "societal framework," and "financial markets." China is 3rd in "labor market." This indicator is derived from labor costs, labor-relations, and the quantity and quality of labor. China's labor costs and quantity are such that it has a high ranking.

Lastly there are the indices related to infrastructure. The gap between Japan and the U.S. is large especially in "basic infrastructure" and "technological infrastructure." "Basic infrastructure" comprises a number of items, such as land area, transportation and energy infrastructure, and the working-age population. "Technological 
infrastructure" refers to the level of dissemination of telecommunications and broadband networks, as well as human elements, such as IT skills and the number of qualified engineers. Japan's aging society lowers its ranking in basic infrastructure, which cannot be helped. However, it does seem rather strange that Japan's technological infrastructure lags that of the U.S. and is at about the same level as China's. A closer examination shows that Japan's ranking is lowered by its ratio of investment in telecommunications costs and infrastructure to GDP.

In summary, the factors that raise Japan's competitiveness ranking are as follows.

- A high per capita GDP and a domestic market with a large population

- The country's science and technology-related activities, as seen by R\&D and patents

- High energy efficiency and an environmentally conscious economic system

- Health and longevity, and a safe and secure living environment

However, the following factors are among those that bring down Japan's ranking.

- Inaction on fiscal deficits and government inefficiency

- An aging society and slowdown of economic activity

- A high cost structure

As we have seen this far, the IMD World Competitiveness Yearbook uses a broad range of indices, and one cannot help but get the sense that it is a hodge-podge of data. However, this shows that international competitiveness is a multi-faceted concept, and these various factors intermix in a complex fashion. In addition, the IMD includes factors that have no direct relationship with economic activities, such as environmental aspects and public safety. Some concepts expand upon the traditional idea of GDP, such as green GDP, which incorporates depletion of natural resources in conjunction with economic activity, or Gross National Happiness (GNH), which measures the overall happiness of a nation's people. The IMD index can also be thought of as extending beyond mere economic performance to encompass environmental and social value aspects.

\subsection{Summary}

In this chapter, we discussed key macro environmental aspects of the world economy as we considered global business strategy. In 1990, developed countries' economies, led by Japan, the U.S., and Europe, comprised more than $80 \%$ of the world's GDP. However, this share has gradually declined, and it is predicted to fall to about $40 \%$ by 2030 . To date, the activities of multinational corporations have focused on developed nations, although the importance of newly industrializing countries such as China and India is continuing to grow. Small developing countries, with 
relatively small amounts of per capita capital accumulation, will have higher GDP growth than developed countries. The per capita GDP (or income levels) will also increase at a faster rate than in the developed countries, although we note that, when we examine the timeline through 2030, the overall picture of developed versus developing nations' income levels does not change. In other words, the economies of developing nations will grow, but "economic distance," explained in the previous chapter, will remain.

Moreover, other distances in global business, particular cultural and administrative distances, are unlikely to decrease rapidly. Developing countries without mature capitalist economies have institutional characteristics that vary by country. These developing countries have a much smaller international flow of people compared with developed nations, so cultural distances are unlikely to be affected by globalization. In other words, developing countries require global strategies that are adapted to each country. Furthermore, it must be kept in mind that the large countries of China and India have CAGE (cultural, administrative, geographic, economic) distances internally as well. These countries have vast disparities in their per capita income levels. In India, the administrative framework varies by state, and regional languages are spoken alongside English and Hindi. To be sure, the major trend is to steer toward global strategies that target newly industrializing countries, but creating specific global strategies will require sufficient awareness of the diversity among the newly industrializing countries.

Open Access This chapter is distributed under the terms of the Creative Commons Attribution Noncommercial License, which permits any noncommercial use, distribution, and reproduction in any medium, provided the original author(s) and source are credited.

\section{References}

Acemoglu, D., Johnson, S., \& Robinson, J. A. (2001). The colonial origins of comparative development: An empirical investigation. American Economic Review, 91, 1369-1401.

Barro, R. J., \& Sala-i-Martin, X. I. (2003). Economic growth. Cambridge: MIT Press.

Grossman and Helpman. (1993). Innovation and Growth in the Global Economy. Cambridge: MIT Press.

IMD. (2013). World competitiveness yearbook. Lausanne: IMD.

Motohashi, K. (2014). The sun rises Again: Revitalization of Japan's industrial competitiveness (Hi ha mata takaku, Sangyo Kyosoryoku no Saisei). Tokyo: Nikkei Publishing Ltd. (in Japanese).

Porter, M. (1990). Competitive advantage of nations. New York: Free Press.

World Bank. (1993). East Asia miracle: Economic growth and public policy. Washington, DC: The World Bank.

World Economic Forum. (2012). WEF index 2012. Geneva: World Economic Forum. 